\title{
O DIREITO REAL DE LAJE COMO INSTRUMENTO DE REGULAMENTAÇÃO FUNDIÁRIA URBANA
}

\section{THE REAL SLAB LAW AS AN INSTRUMENT OF URBAN LAND REGULATION}

\author{
Helena Soares Souza Marques Dias ${ }^{1}$
}

\author{
Márcia Robalo Mafra
}

Resumo: $O$ presente artigo aborda o tema direito de laje como instrumento de regulamentação fundiária urbana. Seu estudo justifica-se diante da necessidade de promover a ampliação do conhecimento sobre este polêmico e atual tema, a fim de esclarecer e dirimir possíveis equívocos na aplicação e interpretação do novel instituto. Tem-se como objetivo geral estudar a natureza jurídica do novel direito real de laje, introduzido no Código Civil pela Lei ${ }^{\circ} 13.465 / 2017$. Como objetivos específicos, buscamos apresentar os conceitos doutrinários de direito real de laje, descrever suas espécies e sujeitos, analisar sua natureza jurídica, distingui-lo de outros direitos reais, abordar suas formas de constituição e de extinção, bem como destacar a importância do direito real de laje como instrumento de regulamentação fundiária urbana no Brasil. Trata-se de uma pesquisa bibliográfica com método de abordagem dedutivo sob análise da legislação constitucional e infraconstitucional. Utiliza-se como referência o Código Civil, a Medida Provisória $n^{\circ} 759 / 2016$ e a Lei $n^{\circ}$ 13.465/2017. Conclui-se que o direito real de laje se trata de direito real autônomo sobre a coisa própria que caracteriza uma extensão do direito de propriedade, tendo como principal finalidade a regulamentação jurídica das construções sobrepostas conhecidas como "puxadinhos".

Palavras-chave: Direito Real de Laje. Direito das Coisas. Direito de

1 Advogada, graduada em Direito pela Universidade da Região da Campanha URCAMP/RS, pós-graduanda em Direito Civil e Direito Processual Civil pela Universidade Católica de Pelotas - UCPel/RS, pós-graduanda em Direito de Família e Sucessões pela Fundação Escola Superior do Ministério Público do Rio Grande do Sul-FMP/RS. Email: hssdias@hotmail.com.

2 Mestre em Direitos Humanos pelo Centro Universitário Ritter dos Reis. Email: marcia. mafra@ucpel.edu.br. 
Propriedade. Regulamentação Fundiária Urbana

Abstract: This article deals with the issue of slab law as an instrument of urban land regulation. Its study is justified by the need to promote the expansion of knowledge about this controversial and current theme, in order to clarify and resolve possible misunderstandings in the application and interpretation of the novel institute. The general objective is to study the legal nature of the real slab right, introduced in the Civil Code by Law 13,465 / 2017. As specific objectives, it has been sought to present the doctrinal concepts of the real right of slab, to describe its species and subjects, to analyze its legal nature, to distinguish it from other real rights, to approach its forms of constitution and extinction, as well as to emphasize the importance of law as an instrument of urban land use regulation in Brazil. It is a bibliographical research with method of deductive approach under analysis of constitutional and infraconstitutional legislation. The Civil Code, Provisional Measure N. 759/2016 and Law N. 13.465 / 2017 are used as reference. It is concluded that the real right of slab is an autonomous real right over the proper thing that characterizes an extension of the right of property, having as main purpose the legal regulation of the overlapping constructions known as "puxadinhos".

Keywords: Royal Slab Law. Right of Things. Property Law. Urban Land Regulation.

\section{INTRODUÇÃ̃O}

Em razão do número elevado de áreas que necessitam de regularização fundiária e imobiliária no Brasil, foi publicada, no Diário Oficial da União do dia 22/12/2016, a Medida Provisória $\mathrm{n}^{\circ} 759$, que ao dispor sobre as regularizações fundiárias urbana e rural, acrescentou o inciso XIII ao artigo 1.225 do Código Civil e instituiu como novo direito real o direito de laje, conceituado no também introduzido artigo 1.510-A do diploma civil.

A Medida Provisória $n^{\circ} 759 / 2016$ foi convertida na Lei $n^{0} 13.465 / 2017$, publicada no Diário Oficial da União em 11/07/2017. Assim, ao rol de direitos reais do art. 1.225 do CC foi acrescentado o inciso XIII, erigindo o direito de laje ao status de direito real.

Em síntese Tartuce (2017) conceitua o instituto como direito real sobre a unidade imobiliária autônoma erigida sobre a propriedade de outrem. No mesmo sentido, Rosenvald (2017) 
descreve o direito real de laje como instrumento de regularização fundiária urbana totalmente adequado à realidade brasileira, "[...] na qual incontáveis famílias vivem em pavimentos distintos daquele originariamente construído sobre o solo". São os popularmente conhecidos "puxadinhos".

Diante da inovação legislativa surgiram inúmeras discussões doutrinárias a respeito da natureza jurídica do instituto: enquanto o legislador e grande parte da doutrina entendem ser um direito real autônomo, alguns entendem se tratar de direito real sobre a coisa alheia, como um desdobramento do direito real de superfície.

Assim, justifica-se o presente estudo pela necessidade de promover a ampliação do conhecimento sobre este polêmico e atual tema, a fim de esclarecer e dirimir possíveis equívocos na aplicação e interpretação dos institutos acima mencionados.

Desse modo, teve-se como objetivo geral estudar a natureza jurídica do novel direito real de laje, introduzido no Código Civil pela Lei $\mathrm{n}^{\circ}$ 13.465/2017.

Os objetivos específicos do trabalho foram apresentar os conceitos doutrinários de direito real de laje, descrever suas espécies e sujeitos, estudar a natureza jurídica do instituto, distingui-lo de outros direitos reais semelhantes e abordar suas formas de constituição e de extinção, a partir da análise da Lei $\mathrm{n}^{\mathrm{o}}$ 13.465/2017 e do Código Civil Brasileiro, bem como destacar a importância do direito real de laje como instrumento de regulamentação fundiária urbana.

\section{DIREITO DAS COISAS E DE DIREITOS REAIS: CONCEITO E PRINCIPAIS CARACTERÍSTICAS DOS INSTITUTOS}

Para Tartuce (2017) Direito das Coisas pode ser conceituado como o ramo do Direito Civil que disciplina as relações 
jurídicas estabelecidas entre pessoas e coisas determinadas ou determináveis, sendo que, para o autor, pode-se entender como coisas tudo aquilo que não é humano ou, ainda, bens corpóreos ou tangíveis sujeitos à apropriação.

O Direito das Coisas é formado, principalmente, mas não de forma exclusiva, pelos "Direitos Reais" que, conforme ensina Tartuce (2017), podem ser conceituados como o conjunto de relações jurídicas existentes entre pessoas e coisas determinadas ou determináveis, fundada no direito de propriedade (que pode ser plena ou restrita). Para o autor, a diferença em relação ao Direito das Coisas é que este se trata de um ramo do Direito Civil, ao passo em que os Direitos Reais constituem as relações jurídicas propriamente ditas.

A partir da doutrina civilista brasileira podem ser apontadas as seguintes características ou caracteres jurídicos dos direitos reais: a) oponibilidade erga omnes, ou seja, contra todos; b) existência de um direito de sequela, ou seja, que segue a coisa; c) existência de um direito de preferência a favor do titular de um direito real; d) possibilidade de renúncia ao direito real; e) possibilidade de incorporação da coisa por meio da posse; f) previsão da usucapião como uma das formas de aquisição; g) obediência a um rol taxativo previsto no Código Civil; e h) observância ao princípio da publicidade dos atos. (EL DEBS et al., 2017; TARTUCE, 2017; GOMES, 2004).

Entretanto, como bem destaca Tartuce (2016), apesar de os direitos reais serem considerados absolutos, no sentido de que possuem eficácia erga omnes, cumpre destacar que o referido absolutismo não significa dizer que o titular de um direito real possui um poder ilimitado sobre o bem que se submete a sua autoridade. Isto ocorre porque, como qualquer outro direito fundamental previsto no ordenamento jurídico pátrio, o direito real é submetido a uma ponderação de valores. Ocorrendo conflito entre direitos fundamentais, como por exemplo entre 
o direito de propriedade e o direito ao meio ambiente, ambos tutelados constitucionalmente, o aplicador do direito deverá utilizar a técnica da ponderação a fim de obter a melhor solução para o caso concreto.

No que diz respeito à existência de um rol taxativo, quanto aos direitos reais previstos no artigo 1.225 do Código Civil, afirma Tartuce (2016) que a doutrina contemporânea vem se insurgindo a respeito. Isto porque, conforme o autor, a lei pode criar, sucessivamente, novos direitos reais. Como exemplo cabe citar a introdução feita pela Lei $\mathrm{n}^{\circ}$ 11.481/2007 de duas novas categorias de direitos reais sobre a coisa alheia: a concessão de uso especial para fins de moradia e a concessão de direito real de uso. Ainda, cita-se o novíssimo direito real de laje, objeto do presente estudo, erigido ao status de direito real pela inclusão do inciso XIII ao artigo 1.225 do Código Civil. Ademais, conforme ensina o autor, novos direitos reais podem ser criados por leis extravagantes sem que sejam descritos expressamente no diploma civil, havendo, desta forma, uma "tipicidade legal dos direitos reais, e não uma taxatividade do art. 1.225 do CC".

\section{O DIREITO REAL DE LAJE COMO INSTRUMENTO DE REGULAMENTAÇÃO FUNDIÁRIA URBANA: CONCEITO E ESPÉCIES}

Conforme referem Farias et al. (2017), nas cidades brasileiras são frequentes as situações em que um filho constrói nova edificação totalmente independente sobre a laje da residência dos pais, com autorização destes, muitas vezes instrumentalizada por documento particular. Tais edificações, construídas à margem da lei, acabavam se tornando fonte de insegurança, incerteza e conflitos para o proprietário do imóvel principal, bem como para o "possuidor" da laje, que dela não possuía nenhum documento válido que assegurasse seu direito de ser titular. São 
os conhecidos "puxadinhos", em que diferentes famílias vivem em pavimentos distintos daquele construído sobre o solo.

Com a finalidade de regulamentar a situação fundiária das unidades imobiliárias popularmente conhecidas como "puxadinhos", até então à margem da lei e sem solução jurídica adequada, a Medida Provisória ${ }^{0}$ 759, de 22 de dezembro de 2016, em um contexto de promoção da segurança jurídica e da regularização fundiária urbana nas moradias sobrepostas, acrescentou o inciso XIII ao artigo 1.225 do Código Civil, instituindo um novo direito real: o direito de laje. Desta forma, com a inovação jurídica, inúmeras pessoas hoje poderão registrar o seu direito, por escritura pública ou particular, de forma autônoma, passando a exercer plenamente os efeitos resultantes da situação.

\subsection{Conceito}

Rosenvald (2017) se refere à laje como uma nova manifestação do direito de propriedade, constituída por uma unidade imobiliária autônoma, construída com matrícula própria, com isolamento funcional e acesso independente, individualização de despesas e encargos econômicos e instituição de titularidade sucessiva.

Contudo, conforme esclarece Farias (2017), caso a construção seja feita de forma interligada ao imóvel principal, tratar-se-á de acessão ou benfeitoria em relação a este, dependendo da finalidade da construção. É o exemplo do pai que constrói não somente uma estrutura para o filho morar, mas também área de lazer ou de serviço que servirá às duas moradias ou, ainda, constrói um acesso interno que vincula os imóveis.

\subsection{Espécies de laje}

Pela simples leitura do artigo 1.510-A é possível reconhecer a existência de duas espécies de laje: por meio de construções verticais superiores (sobrelevadas) e inferiores (utilizando-se o 
espaço descendente da construção-base). Destaca-se que, conforme Farias et al. (2017), no caso de construções horizontais, na mesma linha do imóvel principal, não haverá laje, podendo caracterizar a existência de condomínio urbano simples.

A construção vertical superior, denominada laje em sobrelevação, é a mais comum das espécies de laje. Para Farias et al. (2017), está intimamente ligada à construção principal ou à laje que a antecede, tanto física, quanto juridicamente. Isto porque, uma vez destruída a construção-base, não sendo esta reconstruída no prazo de cinco anos, nos termos do artigo 1.510-E do Código Civil, estará extinta a laje em sobrelevação.

No que diz respeito às construções verticais inferiores, também chamadas de laje em infrapartição, a situação é distinta. Conforme Farias et al. (2017), o vínculo entre o imóvel-base e a laje não será perene, posto que, mesmo que haja a destruição desse, a laje em infrapartição subsistirá. Neste caso, segundo os autores, enquanto não houver a reconstrução do imóvel, a laje passará a ser a construção-base.

\section{NATUREZA JURÍDICA DA LAJE: DIREITO REAL AUTÔNOMO OU DIREITO REAL SOBRE A COISA ALHEIA?}

A Medida Provisória $n^{0} 759 / 2016$, convertida na Lei ${ }^{0}$ 13.465/2017, acrescentou o inciso XIII ao rol de direitos reais do artigo 1.225, do Código Civil, erigindo o direito de laje ao status de direito real. Sendo assim, o legislador foi incisivo ao reconhecer expressamente a natureza jurídica da laje como direito real.

Sendo assim, como bem ensinam Farias et al. (2017), sendo reconhecida a laje como direito real, consequências lógicas serão a transmissão hereditária quando do falecimento do titular, uma vez que se trata de relação jurídica com conteúdo patri- 
monial; a possibilidade de partilha do direito de laje quando da dissolução de casamento ou de união estável do titular; o dever de repartição das despesas comuns relativas ao imóvel, como pintura e manutenção, entre lajeado e lajeário; a possibilidade de se reconhecer ao titular da laje a tutela reivindicatória; e, ainda, a decorrência de encargos tributários proporcionais às dimensões da laje.

No entanto, discute-se se a laje se trata de um direito real autônomo (sobre a coisa própria) ou de um direito real sobre a coisa alheia, sendo importante tal diferenciação tendo em vista os efeitos práticos, que serão distintos, a depender.

A partir da análise da doutrina civilista se verifica a existência de posições distintas no que diz respeito à natureza jurídica do direito real de laje. Parte da doutrina, representada pelos professores Pablo Stolze Gagliano (2017), Flavio Tartuce (2017) e Roberto Paulino de Albuquerque Júnior (2017), entende ser o direito real de laje um direito real sobre a coisa alheia que não se confunde com a propriedade, sendo, portanto, um desdobramento do direito real de superfície. Por outro lado, o legislador e inúmeros autores, como Nelson Rosenvald (2017), Martha El Debs (2017), Cristiano Chaves de Farias (2017) e Wagner Inácio Dias (2017), entendem se tratar de direito real autônomo.

\subsection{A laje como direito real sobre a coisa alheia}

Parcela da doutrina que entende ser o direito de laje um direito real sobre coisa alheia defende que a possibilidade de se construir em sobre levação caracteriza uma extensão do direito de superfície, pertencente ao rol dos direitos reais de uso e fruição, que são de natureza limitada. No dizer de Farias et al. (2017, p. 52), para os defensores desta posição, “[...] o enquadramento topológico da laje decorreria como um novo tipo de direito real de gozo ou fruição, pelo qual o titular autorizaria um terceiro (lajeário) a retirar certas utilidades da coisa". 
Conforme referem Farias et al. (2017), analisando-se a situação por este prisma, o direito do lajeário (titular da laje) seria limitado, sendo um mero acessório do direito de propriedade. Portanto, seria a laje uma espécie de superfície de segundo grau, um desdobramento do direito de superfície. Para justificar tal entendimento, utiliza-se o argumento de que a cessão do direito de laje necessariamente deverá ser averbada na matrícula da construção-base.

Nesse sentido ilustra Stolze (2017), que no caso do sujeito que constrói um segundo andar em sua propriedade, com acesso independente, transferindo-o posteriormente, mediante remuneração, a um terceiro que nele fixa residência, este passa a exercer direito apenas sobre a extensão da construção-base, ou seja, a laje. Desta forma, para o autor, trata-se de direito real sobre a coisa alheia que não pode ser confundido com a propriedade, uma vez que não abrange o solo, limitando-se à unidade imobiliária autônoma erigida sobre a propriedade de outrem.

Na mesma esteira, pontua Albuquerque Júnior (2017), que o direito de laje já é previsto expressamente na legislação brasileira desde 2001 como superfície por sobrelevação, não sendo, portanto, um novo direito real, mas sim uma modalidade de direito de superfície.

Ainda, como bem destacam Farias et al. (2017), os defensores da laje como direito real sobre a coisa alheia argumentam que a chamada sobrelaje, ou seja, a construção de uma nova laje sobre a laje, necessita do consentimento expresso do proprietário do imóvel-base, o que reforça o caráter de assessoriedade do direito real em análise que, conforme o referido entendimento, não existe por conta própria. Porém, para os autores, tal perspectiva não corresponderia à efetiva situação existente no Brasil, onde existem situações concretas de interesses autônomos titularizados pelos lajeários. 


\subsection{A laje como direito real sobre a coisa própria}

Em que pese parcela importante da doutrina civilista contemporânea entenda ser o direito de laje um direito real sobre coisa alheia, o legislador e muitos doutrinadores de renome defendem veementemente ser o direito de laje um direito real autônomo e independente, ou seja, sobre coisa própria, tratando-se, para Rosenvald (2017), de "[...] uma nova manifestação do direito de propriedade".

Farias et al. (2017, p. 49) esclarecem que “[...] a interpretação dos textos jurídicos deve estar atrelada à realidade da vida em sociedade“. Neste sentido, conforme afirmam os autores, o direito real de laje configura um direito real autônomo absolutamente independente em relação à construção-base, uma vez que, pela própria literalidade do artigo 1.510-A, $\S 3^{\circ}$, do Código Civil, assegura-se a abertura de uma matrícula própria para o direito de laje, distinta da matrícula do imóvel originário.

Rosenvald (2017) afirma que:

A laje não é mera projeção laminar de uma propriedade alheia! O legislador enfaticamente disciplinou o novel direito real como uma unidade imobiliária autônoma, construída com matrícula própria, novo fólio distinto daquele que publicizou a construção sobre o solo, com isolamento funcional e acesso independente, individualização de despesas e encargos econômicos e instituição de titularidade sucessiva (art. 1.510-A, $\S \S 1^{\circ}$ a $6^{\circ}, \mathrm{CC}$ ). Se nem toda propriedade é perpétua (v.g. a propriedade resolúvel), o certo é que não existem direitos reais em coisa alheia com o atributo da perpetuidade, pois em algum momento o titular terá que restituir os poderes dominiais ao proprietário. Dentre outras, a enfiteuse foi relegada ao limbo no $\mathrm{CC} / 02$, pois na atualidade um direito real de fruição apenas exercita a sua função social quando há uma demarcação temporal pelo qual o titular extrairá uma utilidade de um bem alheio, evitando-se o parasitismo 'ad eternum'. Além de não ser propriedade demarcada temporalmente, não se trata o direito 
real e laje de direito real limitado em seu conteúdo, o que pressupõe um esvaziamento dos poderes dominiais. O titular da laje poderá usar, fruir, dispor e reivindicar. Evidentemente, há uma limitação na realização de obras/reformas/ instalações na laje, ou exercício de direito de preferência para atos dispositivos. Esse balanceamento é próprio da coexistência de unidades imobiliárias autônomas, como ocorre no condomínio tradicional (modelo jurídico distinto da laje pela comunhão de frações ideais sobre áreas comuns), decorrendo das regras que disciplinam o exercício civilizado dos direitos de vizinhança ou o adimplemento de exigências administrativas, que em nada interferem no conteúdo da propriedade.

Em contraponto aos argumentos daqueles que defendem ser a laje um direito real sobre a coisa alheia caracterizado por uma extensão do direito de superfície, Rosenvald (2017), traça uma análise comparativa entre os institutos em comento. Conforme o autor, existem diferenças básicas em relação aos planos estrutural e funcional dos referidos modelos jurídicos.

Para o autor, no que diz respeito ao plano estrutural, trata-se o direito de superfície de propriedade resolúvel, caracterizada pela suspensão temporária dos efeitos da acessão, uma vez que a construção ou plantação realizada no solo terá como titular o construtor pelo prazo avençado entre as partes. Findo o prazo previsto na averbação do registro do imóvel, cancelado estará o direito real de superfície. Por outro lado, como bem ensina o autor, trata-se o direito de laje de propriedade perpétua, que tem como característica principal o registro de uma matrícula autônoma no Registro Geral de Imóveis, totalmente independente da matrícula da construção-base.

No que tange ao plano funcional de ambos os institutos jurídicos, refere Rosenvald (2017), que no direito real de superfície existe um nexo finalístico entre a construção ou plantação e o imóvel, uma vez que "a superfície encontrará utilidade em investimentos econômicos que demandem ex- 
ploração de propriedades ociosas", como áreas abandonadas ou prédios que necessitem de reformas ou, ainda, para o desempenho da função social das cidades. Por outro lado, o direito real de laje possui finalidades diversas, tratando-se de um novo instrumento de regularização fundiária urbana que democratiza o direito de propriedade.

\subsection{A laje como nova manifestação do direito de propriedade}

Na visão de Rosenvald (2017), trata-se o direito real de laje de "uma nova manifestação do direito de propriedade", que se coaduna com a concepção constitucionalizada do Direito Civil e que vence a visão tradicional de que o direito de propriedade só é possível quando o imóvel estiver fisicamente atrelado ao solo. Isto porque, conforme o autor, não se pode ignorar a contemporânea "realidade plural das propriedades", constituídas, além da propriedade mobiliária, também por titularidades intangíveis como patentes, propriedades autorais e softwares.

No entendimento de Rosenvald (2017), com a tipificação do direito de laje com a vigência da Lei $n^{\circ}$ 13.465/2017

[...] abre-se um novo capítulo na constante ressignificação do direito de propriedade brasileiro, resultado da necessária tensão entre o "direito de propriedade" e o "direito à propriedade". O direito de propriedade (art. $5^{\circ}, \mathrm{XXII}, \mathrm{CF}$ ) como garantia institucional e direito fundamental individual, fundado na liberdade do indivíduo de se apropriar de bens e de excluir terceiros (o clássico sujeito passivo universal). Lado outro, o direito à propriedade (art. $5^{\circ}$, 'caput', $\mathrm{CF}$ ), como expressão do Estado Democrático de Direito pela via da universalização do acesso à propriedade. Trata-se de direito fundamental social, albergado no princípio da igualdade material, que defere a todo o ser humano o "vir a ter" e o direito de "não ser excluído" da condição de cidadão dotado de um piso patrimonial que materialize a sua dignidade e preserve a privacidade do núcleo familiar. 
Nesse sentido, entende o autor que a adequação entre o direito de propriedade e o direito à propriedade, como mínimo existencial, insere o direito de laje como um instrumento de regularização fundiária urbana que se adequa a realidade das famílias brasileiras, em especial as de baixa renda. Isto porque é frequente a existência de núcleos familiares que vivem em pavimentos distintos da construção original, assumindo a condição de "possuidores" da laje. Ademais, assevera o autor que a regularização jurídica do então fato social o converte em "membro da cidade formal".

Para Farias et al. (2017), não é possível reduzir o direito de laje a um mero acessório do direito de propriedade, uma vez que o titular da laje possui um direito detentor de funcionalidade própria e sobre o qual exerce os atributos inerentes à propriedade (usar, gozar, dispor e reivindicar), podendo inclusive oferecer sua laje em garantia. Ainda, referem os autores que o direito real de laje está encaixado em uma perspectiva finalística que garante a todos os seres humanos o direito de atingir um mínimo existencial que possa efetivar a sua dignidade e de sua família.

\subsection{A laje como direito fundamental constitucional}

De acordo com Farias et al. (2017), o direito de propriedade, a partir da Revolução Francesa, apresentou-se como o mais amplo e ilimitado de todos os direitos patrimoniais, baseando-se sua interpretação em uma perspectiva patrimonialista econômica. Porém, ao ser erigido ao status de direito fundamental pela Carta Magna de 1988, o direito de propriedade passou a ser considerado como garantia mínima para o exercício da cidadania, ao lado de outros valores essenciais à dignidade humana como a liberdade e a igualdade material, passando então a receber novos contornos e interpretações.

A Constituição Federal elenca o direito de propriedade como direito fundamental em seu artigo $5^{\circ}$, principalmente no 
inciso XIII, que afirma estar "garantido o direito de propriedade". Desta forma, conforme os autores, trata-se o direito de propriedade de um direito fundamental vinculado ao mínimo existencial e à dignidade da pessoa humana, estando intimamente ligado a uma perspectiva existencial.

Ademais, conforme ensinam Farias et al. (2017), de acordo com entendimento doutrinário e jurisprudencial, bem como a partir da análise do $\S 2^{\circ}$ do artigo $5^{\circ}$ da Constituição Federal, o rol dos direitos fundamentais trazidos pela Carta Magna é meramente exemplificativo, uma vez que podem estar elencados no texto constitucional ou podem decorrer de princípios fundamentais, estes chamados de princípios implícitos.

Nessa esteira, asseveram Farias et al. (2017) que o direito de laje deve ser reconhecido como um direito fundamental implícito, tratando-se de simples decorrência do caráter fundamental do direito de propriedade, uma vez que se trata de nova manifestação deste. Ademais, o direito de laje é considerado um direito fundamental tendo em vista a sua finalidade de assegurar a dignidade da pessoa humana sob o prisma do direito à moradia e do direito ao referencial espacial conferido às pessoas.

Diante disso, refere Marmelstein apud Farias et al. (2017) que se o proprietário do imóvel-base é titular de direitos fundamentais, o lajeário também o será, posto que se busca a proteção do mínimo existencial e da moradia, como expressão da dignidade humana.

Então, conforme ensinam Farias et al. (2017), reconhecendo-se o direito de laje como um direito fundamental, a ele serão concedidos todos os efeitos decorrentes desse enquadramento. Portanto, deverá o direito de laje ser tratado como cláusula pétrea, não podendo ser objeto de retrocesso (diminuição de sua proteção). Ainda, como decorrência do caráter fundamental do direito de laje, reconhece-se a sua impenhorabilidade, ou seja, 
não poderá a laje ser objeto de penhora, ainda que o seu titular não resida nela, mas utilize seus rendimentos para sua subsistência e dignidade. Por outro lado, deverá o titular da laje atender aos fins sociais da propriedade, conforme exigido do proprietário pelo texto constitucional.

\section{DIREITOS E OBRIGAÇÕES DAS PARTES}

Como em todas as relações jurídicas, as partes que compõem o contexto em que existe um direito real de laje possuem direitos e obrigações recíprocos, apontados pela doutrina como se verá adiante.

\subsection{Direitos e deveres do lajeado}

Farias et al. (2017) elencam em sua obra diversos direitos pertencentes ao proprietário do imóvel, chamado de lajeado. O primeiro deles é o direito de ter mantida intacta a propriedade do terreno sobre o qual está edificada a construção-base, uma vez que as propriedades pertencentes ao lejeado e ao lajeário são autônomas, não havendo que se falar em propriedade comum ou frações ideais, conforme se depreende da leitura do $\S 4^{\circ}$ do artigo 1.510-A do Código Civil. Como decorrência a inexistência de vínculo entre as propriedades, o segundo direito apontado diz respeito à individualidade de cada imóvel em relação às contribuições e tributos, que serão próprios e independentes. Sendo assim, a cada nova laje construída será reconhecida nova matrícula e, consequentemente, será criada uma diferente unidade tributável.

O terceiro direito que toca ao lajeado, conforme os referidos autores, trata-se daquele previsto no $\S 2^{\circ}$ do artigo 1.510-A do Código Civil, pelo qual poderão tanto o lajeado quanto o lajeário, em casos de urgência, providenciar o reparo necessário, sendo-lhe conferido o direito de cobrar daquele que não contribuiu. Ademais, figura como direito do lajeado o de se 
opor à constituição de novos direitos de laje, ou seja, de sobrelajes. Desta forma, pretendendo o lajeário constituir nova laje, deverá o lajeado dar o seu consentimento expresso.

Por fim, o último e um dos principais direitos do lajeado citado por Farias etal. (2017) se trata da prioridade na preferência para aquisição da laje caso esta venha a ser alienada onerosamente, conforme expresso no artigo 1.510-D do Código Civil.

Farias et al.(2017), citam em sua obra três deveres que tocam ao lajeado: o de contribuir com as áreas que servem à construção, arcar com as despesas urgentes, bem como reconstruir a construção-base em caso de ruína desta.

Em primeiro lugar, conforme esclarecem os autores acima citados, o fato de grande parte das áreas que sirvam ao prédio estarem ligadas à construção-base não significa dizer que os custos com a sua manutenção deverão ser arcados exclusivamente pelo lajeado ou então que este terá uma proporção maior na divisão de despesas. A proporção deverá ser feita no instrumento de cessão da laje, de acordo com o proveito que cada imóvel auferirá.

O segundo dever que toca ao lajeado, bem como ao lajeário, não apresenta grandes debates: trata-se do dever de realizar reparações urgentes em áreas que sirvam a toda edificação, podendo posteriormente cobrar o valor que caberia ao lajeário.

O terceiro e último dever do lajeado, citado pelos doutrinadores, se refere à obrigatoriedade deste de reconstruir a construção-base no prazo de cinco anos, caso esta venha a ruir, nos termos do inciso II do artigo 1.510-E, do Código Civil. Caso o lajeado não providencie a reconstrução no prazo estabelecido, estará extinto o direito real de laje, restando autorizado o lajeado a realizar a reconstrução do prédio-base, atribuindo-se a ele a propriedade do conjunto. 


\subsection{Direitos e deveres do lajeário}

Segundo Farias et al.(2017), o primeiro e mais polêmico direito que toca ao lajeário diz respeito ao acesso independente a sua laje, exigido pela redação inicial do $\S 3^{\circ}$ do artigo 1.510A do CC, não reproduzida pela redação final. Desta forma, não é necessária a existência de acesso independente à laje para que esta se configure. No entanto, havendo possibilidade física, possui o lajeário o direito de edificar um acesso independente para a laje, podendo inclusive se utilizar de fração do terreno do proprietário da construção-base.

Como segundo direito inerente ao lajeários e vislumbra a possibilidade de este ser cobrado pelos tributos e encargos que recaiam apenas sobre a sua laje.

Possui também o lajeário os atributos inerentes à propriedade: usar, gozar, dispor e reivindicar, conforme explanado anteriormente. Desta forma, de acordo com os ensinamentos de Farias et al. (2017), poderá o lajeário ( $i$ ) utilizar o imóvel como bem lhe aproveitar, desde que dentro dos limites legais; (ii) colher os frutos da laje decorrentes, sejam eles naturais ou civis, bem como se aproveitar dos produtos advindos do imóvel; (iii) alienar a laje a qualquer título ou permitir que sobre ela incida qualquer tipo de ônus, respeitando o direito de preferência do lajeado e dos demais lajeários; e (iv) reivindicar a coisa contra quem injustamente a possua ou detenha, configurando o chamado direito de sequela. Caso deseje constituir nova laje (sobrelaje), dependerá de autorização do proprietário do imóvel-base e dos demais lajeários.

Ademais, referem Farias et al. (2017), que o lajeário terá garantido o direito à posse da laje, podendo se utilizar das medidas necessárias para tutelá-la, ou seja, poderá ingressar com os interditos possessórios.

Cabe também ao lajeário, de acordo com os ensinamentos 
dos autores acima citados, o direito de preferência, em igualdade de condições com terceiros, caso o proprietário do imóvel-base ou algum dos titulares de outras lajes pretenderem alienar, onerosamente, a sua parte.

Finalmente, como último direito do lajeário, referem Farias et al. (2017, p. 87) à discutida e polêmica "[...] possibilidade que o lajeário (sempre da laje superior) venha a adquirir, em razão da não reconstrução da edificação-base, a propriedade do referido espaço para que, nele, possa levantar nova construção".

No que tange aos deveres do lajeário, dispõe $\mathrm{o} \S 2^{\circ}$ do artigo 1.510-A do Código Civil que "[...] o titular do direito real de laje responderá pelos encargos e tributos que incidirem sobre a sua unidade". Sendo assim, conforme os ensinamentos de Farias et al. (2017), da mesma forma que não é possível que o ente público, com competência tributária, execute o lajeário por dívidas oriundas da construção-base, também não poderá ser exigido do lajeado comprovante de regularidade dos tributos do imóvel-base quando da confecção e registro da escritura do direito de laje.

Embora não haja áreas em comum entre a construção-base e a laje e a propriedade das áreas seja atribuída exclusivamente aos seus titulares, todos deverão contribuir com a conservação do prédio, podendo a divisão ser feita livremente pelas partes. Da mesma forma que cabe ao lajeado a realização de obras urgentes, o lajeário possui o mesmo dever. Poderá, posteriormente, caso haja oposição dos demais em efetivar o pagamento, ingressar com ação de regresso para cobrar o valor despendido.

Ademais, conforme explanado anteriormente, é dever de ambas as partes (lajeado e lajeário) respeitar o direito de preferência quando houver a pretensão de alienar sua parte onerosamente a terceiros. Sendo assim, caso pretenda o lajeário alienar sua laje, deverá oferecê-la, primeiramente, ao lajeado e, se este não exercer seu direito, deverá a laje então ser ofe- 
recida aos demais lajeários.

\section{PRINCIPAIS FORMAS DE CONSTITUIÇÃO DO DIREITO DE LAJE}

Por serem oponíveis erga omnes, o regime de aquisição dos direitos reais é próprio e diferenciado. Como regra, poderá o direito real de laje ser adquirido através de negócio jurídico (inter vivos ou causa mortis), porém nada impede que a aquisição se dê por outros mecanismos, conforme demonstrado a seguir.

\subsection{A possibilidade de constituição do direito real de laje por negócios jurídicos}

No dizer de Azevedo (apud TARTUCE, 2016, p. 221), o negócio jurídico "[...] constitui a principal forma de exercício da autonomia privada, da liberdade negocial", tratando-se, de um ato jurídico pelo qual as partes realizam uma composição de interesses com uma finalidade específica.

Sendo assim, de acordo com Farias et al. (2017), é plenamente possível a constituição de direitos reais por meio de negócios jurídicos, podendo estes servirem para a aquisição, transferência ou modificação daqueles. Para tanto, a lei exige como condição de validade do negócio jurídico que diga respeito a direitos reais que a manifestação de vontade das partes se dê por meio de um instrumento público que deverá ser lavrado em cartório: a escritura pública.

Ademais, conforme determina o artigo 172 da Lei $\mathrm{n}^{\circ}$ 6.015/73 (Lei dos Registros Públicos), as escrituras públicas que digam respeito a direitos reais sobre imóveis deverão ser averbadas e registradas no Cartório de Registro de Imóveis. No entanto, de acordo com o artigo 108 do Código Civil, se o valor do imóvel for inferior a trinta salários mínimos a lavratura de escritura pública é dispensada, podendo o negócio 
jurídico ser efetivado por meio de instrumento particular.

Por todo o exposto, resta clara a possibilidade da constituição de direito real de laje por meio de negócio jurídico, o que, para Farias et al. (2017), será a regra. Conforme os autores, através de um negócio jurídico celebrado inter vivos, como doação ou compra e venda, ou através de um negócio jurídico para depois da morte, como é o caso do testamento, poderá o titular do imóvel-base conceder a sua laje a terceiro, constituindo um direito real autônomo e independente: o direito real de laje. Para ilustrar, os autores apresentam a situação em que os pais oferecem aos filhos a laje de seus imóveis para que os filhos edifiquem um novo imóvel, autônomo e independente, que servirá de lar à nova família: os popularmente conhecidos "puxadinhos".

Seguindo a regra, deverá o negócio jurídico ser celebrado por escritura pública, caso o valor do imóvel exceda a trinta salários mínimos, não havendo esta necessidade se o imóvel não exceder referido valor. No entanto, em ambos os casos, para que o direito real de laje seja efetivamente adquirido, deverá o instrumento constitutivo do negócio jurídico ser levado a registro no Cartório de Registro de Imóveis para abertura de uma nova matrícula que será autônoma e totalmente independente a do imóvel-base, conforme prevê o $\S 3^{\circ}$ do artigo 1.150-A do Código Civil.

\subsection{A usucapião lajeária}

O entendimento da doutrina civilista é no sentido de que os direitos reais suscetíveis à posse e não apenas à propriedade são passíveis de aquisição originária pelo decurso do tempo através de usucapião.

Sendo assim, de acordo com os ensinamentos de Farias et al. (2017), tendo em vista que o direito de laje é passível de posse, existe a possibilidade de aquisição originária da laje através da usucapião lajeária. Desta forma, com a decisão judicial que reconhecer a usucapião lajearia o direito real será 
bipartido: o imóvel originário permanecerá com o seu titular, mas será reconhecido ao usucapiente o direito de laje.

Para os autores acima citados, para que ocorra a usucapião lajeária é exigido o preenchimento de todos os requisitos das espécies de usucapião previstas no ordenamento jurídico brasileiro, entre eles a posse ininterrupta, mansa, pacífica durante o lapso temporal exigido pela lei para cada espécie, bem como o ânimo de dono. Para preencher este último requisito, como não se trata do "animus dominii" propriamente dito, deverá o usucapiente provar que sempre agiu como lajeário, que a laje sempre possuiu acesso autônomo e independente e que sempre arcou com as despesas geradas pela laje.

\subsection{A constituição do direito real de laje por declaração unilateral de vontade}

Conforme Farias et al. (2017), além das possibilidades de constituição de direito real de laje já citadas, pode o aludido direito real ser constituído também através de uma declaração unilateral de vontade do proprietário do imóvel originário, independentemente da concordância de eventual beneficiário.

Desta forma, conforme ilustram os autores acima referidos, nada impede que o proprietário do imóvel-base, visando negócios e lucros futuros, venha a instituir direito real sobre a sua laje para, posteriormente, aliená-la. Para tanto, deverá a laje preencher os requisitos exigidos pela legislação, ou seja, deverá ter acesso autônomo e independente em relação à construção-base, bem como autorização do Poder Público.

\subsection{A constituiçãa de lajes sucessivas (sobrelaje)}

O legislador civil, ao disciplinar o direito real de laje, trouxe a possibilidade de o lajeário ceder a sua laje para que seja constituída uma nova laje, desde que preenchidos os requisitos elencados no dispositivo legal: autorização expressa dos 
titulares da construção-base e dos demais lajeários e respeito às normas urbanísticas. Trata-se da denominada sobrelaje ou lajes sucessivas, com previsão expressa no artigo 1.510-A, $\S$ $6^{\circ}$, do Código Civil.

Para Farias et al.(2017), a "[...] sobrelaje configura uma extensão vertical do direito de laje", o que permite que o lajeário institua sucessivas lajes, sejam elas em linha ascendente (espaço aéreo) ou descendente (subsolo), cada uma delas possuindo independência e acesso autônomo. Nesse sentido, da mesma forma que a usucapião exige que a construção-base esteja regularizada, para que seja reconhecida nova matrícula para a sobrelaje é necessário que o imóvel-base e as demais lajes também estejam regularizados, ou seja, devidamente registrados no Cartório de Registro de Imóveis.

\section{FORMAS EXTINTIVAS DO DIREITO REAL DE LAJE}

Ao falarmos sobre as formas de extinção do direito real de laje, encontramos no artigo 1.510-E do Código Civil duas particularidades aplicáveis somente à laje:

Art. 1.510-E. A ruína da construção-base implica extinção do direito real de laje, salvo:

I - se este tiver sido instituído sobre o subsolo;

II - se a construção-base não for reconstruída no prazo de cinco anos.

Parágrafo único. $\mathrm{O}$ disposto neste artigo não afasta o direito a eventual reparação civil contra o culpado pela ruína.

No entanto, o dispositivo legal supramencionado apenas relaciona a extinção do direito real de laje com a ruína do imóvel-base, não abordando as outras formas de extinção dos direitos reais, em especial do direito de propriedade, previstas no 
ordenamento jurídico brasileiro, que devem ser aplicadas ao direito de laje.

Conforme ensinam Farias et al. (2017), assim como o direito de propriedade, o direito de laje é perpétuo, extinguindo-se somente por vontade expressa de seu titular ou então por expressa determinação legal. São aplicáveis, em regra, ao direito real de laje, os mesmos modos de extinção do direito de propriedade previstos no artigo 1.275 do Código Civil, quais sejam, a alienação, a renúncia, o abandono, o perecimento do objeto e a desapropriação, sendo tal rol meramente exemplificativo. Destaca-se que tais formas de extinção são classificadas como voluntárias ou involuntárias.

\subsection{Formas voluntárias de extinção do direito de laje}

Farias et al. (2017) trazem como formas voluntárias de extinção do direito de propriedade aplicáveis à laje a alienação, a renúncia e o abandono.

Os autores acima mencionados conceituam alienação como a forma de extinção da laje através da qual o titular da laje (lajeário) transfere seu direito real a terceiro, seja de forma onerosa (através de uma compra e venda, por exemplo) ou de forma gratuita (por meio de uma doação), devendo o respectivo título translativo ser devidamente registrado no Cartório de Registro de Imóveis para que produza seus efeitos.

Por outro lado, para os autores supracitados, trata-se a renúncia do ato pelo qual o lajeário abdica do seu direito real, sendo ato de vontade unilateral e voluntário que deverá ser levado a registro no Cartório de Registro de Imóveis para que produza seus efeitos legais, assim como a alienação.

Por fim, o abandono também é tratado por Farias et al. (2017) como forma voluntária de extinção do direito real de laje em que o titular abre mão do seu direito. No entanto, seria 
uma forma de abdicação tácita, tendo em vista que o lajeário não abdica de seu direito de forma expressa, mas simplesmente não exerce o seu direito e exterioriza através de ações a vontade de se desfazer do imóvel, sendo necessária a inequívoca prática de atos que evidenciem sua vontade de não conservar o bem em seu patrimônio.

\subsection{Formas involuntárias de extinção do direito de laje}

No que diz respeito às formas involuntárias de extinção da laje, Farias et al. (2017) elencam o perecimento do objeto e a desapropriação.

Afirmam os autores que caso haja o perecimento do objeto, estará extinto o direito, conforme prevê o artigo 1.275, IV, do Código Civil, aplicável ao direito real de laje. A título exemplificativo, caso o prédio constituído em lajes venha a ser destruído por um incêndio, se os titulares optarem pela não reconstrução do edifício, o direito dos lajeários estará extinto, restando apenas o direito do lajeário sobre o terreno.

Já com relação à desapropriação, Farias et al. (2017) a descrevem como instituto de Direito Público de alçada do Direito Administrativo, mas que vem elencado no artigo 1.275, V, do Código Civil, como forma de extinção do direito de propriedade, sendo aplicável também à laje. Para os autores, a desapropriação pode ser conceituada como o modo de perda da propriedade através do qual o proprietário é obrigado a entregar o imóvel de sua titularidade ao Poder Público mediante prévia e justa indenização em dinheiro, nos termos da Constituição Federal e do artigo 1.228, $\S 3^{\circ}$ do Código Civil.

\section{CONCLUSÃO}

Pela pesquisa realizada, mostrou-se que o novel instituto do direito real de laje, instituído pela Lei $\mathrm{n}^{\mathrm{o}} 13.465 / 2017$, 
trata-se de matéria inovadora e controversa no ordenamento jurídico pátrio, tratando-se de invenção tipicamente brasileira que decorre da premente necessidade de o ser humano ter uma referência espacial a fim de suprir uma de suas necessidades básicas de sobrevivência: a moradia. Porém, denota-se que estudos relacionados ao tema ainda são escassos e a jurisprudência é inexistente. Apesar disso, o legislador trouxe uma grande novidade ao abordar o assunto, que traz grandes implicações jurídicas no Direito das Coisas.

Com relação à conceituação e natureza jurídica do direito real de laje, alinhamos com a ideia de que este se trata de um direito real sobre coisa própria, referente a uma unidade imobiliária autônoma e independente, erigida sobre a propriedade de outrem, porém isolada funcionalmente e com acesso próprio, a qual é reconhecida matrícula própria no Registro de Imóveis, sendo suas despesas e encargos econômicos individualizados.

No que diz respeito às espécies, mostramos que existe a possibilidade de a laje ser constituída de duas formas, ambas concretizadas em construções verticais: através da sobrelevação da construção-base (laje superior), bem como através da utilização do espaço descendente da construção-base (laje inferior). Quanto aos sujeitos, demonstrou-se a existência do lajeado - titular do imóvel originário - e do lajeário - titular da laje.

Com relação à diferenciação entre o direito real de laje e os demais direitos reais verificou-se que parte minoritária da doutrina entende que esse se trata de um direito real sobre a coisa alheia, enquanto que a doutrina predominante entende ser um direito real autônomo sobre a coisa própria, caracterizando extensão do direito de propriedade.

No que tange às formas de constituição do direito real de laje, observou-se que este pode ser constituído por meio de negócios jurídicos (sendo exigido para tanto que a declaração de 
vontade das partes seja externada através de escritura pública), por usucapião (uma vez que a laje é passível de posse), por ato unilateral de vontade (nas ocasiões em que o próprio titular do imóvel-base constitui a laje visando alguma finalidade), bem como pela instituição de lajes sucessivas (sobrelaje).

No que diz respeito às formas de extinção do direito real de laje, constatou-se que esta pode ocorrer a perda da laje nos casos de ruína do imóvel base (salvo quando a laje tiver sido instituída de forma descendente ou quando a construção-base não for reconstruída no prazo de cinco anos, conforme dispõe o artigo 1.510-E do Código Civil). Ainda, haverá a extinção da laje nos casos de perda do direito de propriedade, o que pode ocorrer de forma voluntária através da alienação, da renúncia e do abandono, e de forma involuntária pelo perecimento do objeto e pela desapropriação.

Outrossim, destacou-se a importância do direito real de laje como instrumento de regulamentação fundiária urbana que busca a solução da problemática dos popularmente conhecidos "puxadinhos", tendo em vista a frequente situação de unidades imobiliárias sobrepostas, construídas à margem da lei, geralmente pela população de baixa renda, em que vivem diversos núcleos familiares. Por fim, demonstrou-se que o direito real de laje possui a finalidade de garantir a todos os seres humanos o direito ao mínimo existencial que possa efetivar a sua dignidade e de sua família.

\section{REFERÊNCIAS}

ALBUQUERQUE JÚNIOR, Roberto Paulino de. O direito de laje não é um novo direito real, mas um direito de superficie. Disponível em: $<$ https://www.conjur.com.br/ 2017-jan-02/direito-laje-nao-direito-real-direito-superficie>. Acesso em: 26 fev. 2018.

BRASIL. Código civil, Lei 10.406, de 10 de janeiro de 2002. Disponível em: <http:// www.planalto.gov.br/ccivil_03/leis/2002/L10406compilada.htm>. Acesso em: 28 de fev. 2018. 
ccivil_03/constituicao/constituicao.htm>. Acesso em: 27 fev. 2018.

. Lei de Registros Públicos, Lei 6.015, de 31 de dezembro de 1973. Disponível em: $<$ http://www.planalto.gov.br/ccivil_03/leis/L6015compilada.htm>. Acesso em: 27 fev. 2018.

Medida Provisória 759, de 22 de dezembro de 2016. Disponível em: <http:// www.planalto.gov.br/ccivil_03/_ato2015-2018/2016/Mpv/mpv759.htm?TSPD_101 $\mathrm{R} 0=4273 \mathrm{~b} 36 \mathrm{c} 12 \mathrm{bba} 67 \mathrm{bc} 563 \overline{\mathrm{c}} \mathrm{ce} 5377 \mathrm{~d} 312 \mathrm{si} 90000000000000000 \mathrm{f} 24 \mathrm{c} 4 \mathrm{fb} 1 \mathrm{fff}-$ f00000000000000000000000000005af32e4100e3571087>. Acesso em: 26 fev. 2018.

DIAS, Wagner Inácio; EL DEBS, Martha; FARIAS, Cristiano Chaves. Direito de laje: do puxadinho à digna moradia. Salvador: Editora Juspodivm, 2018.

FARIAS, Cristiano Chaves de. O puxadinho virou lei: a Lei n. 13.465/17 e a disciplina do direito real à laje. Disponível em: <http://meusitejuridico.com.br/2017/07/14/o-puxadinho-virou-lei-lei-n-13-46517-e-disciplina-direito-real-laje/>. Acesso em: 27 fev. 2018.

GOMES, Orlando. Direitos reais. Atualizador Luiz Edson Fachin. 19. ed. Rio de Janeiro: Forense, 2004.

ROSENVALD, Nelson. O direito real de laje como nova manifestação de propriedade. Disponível em: <https://www.nelsonrosenvald.info/single-post/2017/09/14/O-direito-real-de-laje-como-nova-manifesta $\% \mathrm{C} 3 \% \mathrm{~A} 7 \% \mathrm{C} 3 \% \mathrm{~A} 30$-de-propriedade $>$. Acesso em: 27 fev. 2018.

STOLZE, Pablo. Direito real de laje: primeiras impressões. Disponível em: $<$ http:// www.revistas.unifacs.br/index.php/redu/article/view/4740/3103>. Acesso em: 27 fev. 2018.

STOLZE, Pablo; VIANA, Salomão. Direito real de laje: finalmente, a lei! Disponível em: <https://salomaoviana.jusbrasil.com.br/artigos/478132365/direito-real-de-laje-finalmente-a-lei>. Acesso em: 28 fev. 2018.

TARTUCE, Flávio. Direito civil: direito das coisas. 9. ed. rev. atual. e ampl. Rio de Janeiro: Forense, 2017. $4 \mathrm{v}$.

TARTUCE, Flávio. Manual de direito civil: volume único. 6. ed. rev. atual. e ampl. Rio de Janeiro: Forense; São Paulo: MÉTODO, 2016.

Recebido em: 29/05/2018

Aprovado em: 07/08/2018 